JOURNAL OF
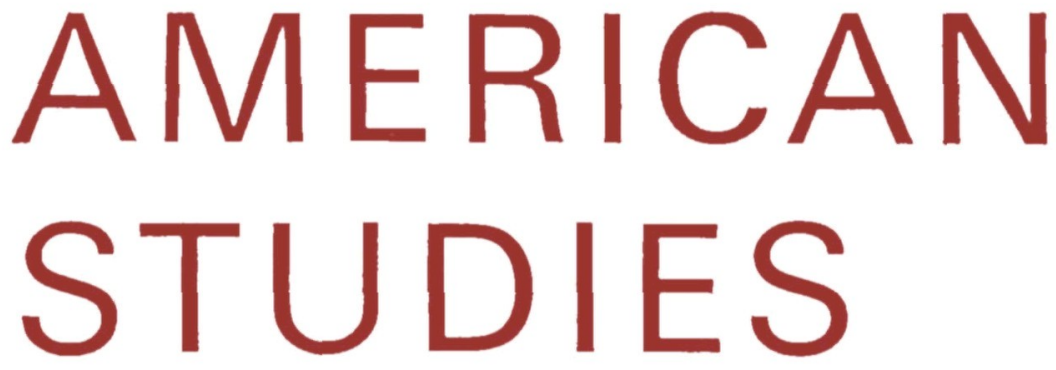

\title{
Cambridge University Press
}

for the British Association for American Studies 
JOURNAL OF

\title{
AMERICAN STUDIES
}

\author{
EDitor: Professor Dennis Welland \\ University of Manchester
}

EDitorial BOARD: Professor Malcolm Bradbury

University of East Anglia

Professor Marcus Cunliffe

University of Sussex

Dr Charlotte Erickson

London School of Economics

Dr Philip Haffenden

University of Southampton

Professor D. G. MacRae

London School of Economics

Professor H. G. Nicholas

New College, Oxford

Dr J. R. Pole

Churchill College, Cambridge

Professor G. A. Shepperson

University of Edinburgh

\section{Professor Henry Nash Smith University of California, Berkeley \\ Professor C. VanN Woodward Yale University}

The Journal aims to promote the study of the history, institutions, literature and culture of the United States.

It publishes work by specialists of any nationality on American history, literature, politics, geography and related subjects. Articles which cross the conventional lines of those disciplines are welcome, as are comparative studies of American and other cultures. It also disseminates information about work in progress and provides a platform for the exchange of scholarly information and opinion.

The editorial policy is not committed to any political viewpoint or ideology, but will not preclude responsible discussion of controversial topics.

Subscriptions. The Journal is published three times a year. The annual subscription is $£_{4.00}$ net U.K. (U.S.A. \$12.50); single parts are available at $£_{2.00}$ net U.K. (U.S.A. \$6.50) each, plus postage. Orders should be sent to your usual bookseller or subscription agent, or direct to Cambridge University Press, Bentley House, 200 Euston Road, London NWI 2DB, or, in U.S.A. and Canada, Cambridge University Press, 32 East 57th Street, New York, N.Y. 10022. Claims for missing issues should be made immediately after receipt of the next issue.

Advertising. Enquiries about advertising in this journal should be sent to the publishers. 